\title{
Should PEEP Titration Be Based on Chest Mechanics in Patients With ARDS?
}

\author{
Richard H Kallet MSc RRT FAARC
}

\author{
Introduction \\ Pro Argument: PEEP Titration Should Be Based on Chest Mechanics \\ The Relationship Between PEEP, $\mathrm{C}_{\mathrm{RS}}$, FRC, and Oxygenation \\ Ventilator-Induced Lung Injury: Shifting Emphasis From Oxygenation \\ to Monitoring Stress-Strain Relationships During PEEP and $V_{T}$ \\ Titration in ARDS \\ Setting PEEP According to Pressure-Volume Curves \\ Application of PEEP Guided by Stress Index \\ Utilizing Esophageal Manometry to Set PEEP \\ Con Argument: PEEP Titration Should Not Be Based on Chest Mechanics \\ PEEP and Its Relationship to Quasi-Static Compliance and FRC \\ Application of PEEP Guided by Stress Index \\ Setting PEEP According to Pressure-Volume Curves \\ The Role of Esophageal Manometry in Setting PEEP \\ Dead-Space Fraction and Optimal PEEP \\ Uncertainty Regarding the Notion of Recruitment and De-Recruitment \\ in ARDS \\ Clinical Implications
}

Functional residual capacity (FRC) is essentially the alveolar volume and a determinant of both oxygenation and respiratory system compliance $\left(C_{R S}\right)$. ARDS decreases FRC, and sufficient PEEP restores FRC; thus, assessments of PEEP by its impact on oxygenation and $C_{R S}$ are intimately linked. PEEP also can ameliorate or aggravate ventilator-induced lung injury. Therefore, it can be argued that PEEP should be titrated primarily by its impact on $\mathrm{C}_{\mathrm{RS}}$. The pro position argues that the heterogeneous nature of lung injury and its unique presentation in individual patients results in an uncoupling between oxygenation and $\mathrm{C}_{\mathrm{RS}}$. Therefore, relying upon oxygenation alone may enhance lung injury and mortality risk, particularly in those with severe ARDS. The con argument is that the preponderance of preclinical and clinical evidence suggests that a relatively narrow range of PEEP is required to manage all but the most severe cases of ARDS. In addition, pathological alterations in chest wall compliance confuse the interpretation of chest mechanics. Moreover, ambiguities and technical limitations in advanced techniques, such as esophageal manometry and pressure-volume curves, add a layer of complexity that renders its broader application in all ARDS patients both impractical and unnecessary. Whether sophisticated monitoring of chest mechanics in severe ARDS might improve outcomes further is open to question and should be studied further. However, it is highly improbable that we will ever discover a PEEP strategy that optimizes all aspects of cardiorespiratory function and chest mechanics for individual patients suffering from ARDS. Key words: ARDS; alveolar recruitment; functional residual capacity; PEEP respiratory system compliance; stress index; transpulmonary pressure; ventilator-induced lung injury. [Respir Care 2016;61(6):876-890. @ 2016 Daedalus Enterprises] 


\section{PEEP Titration Based on Chest Mechanics in ARDS}

\section{Introduction}

The problem of how to set PEEP is complicated partly because clinicians often discuss PEEP in a subliminal manner characterized by something like this. Functional residual capacity (FRC) is essentially the alveolar volume and as such is one of the most important determinants of both oxygenation and respiratory system compliance $\left(\mathrm{C}_{\mathrm{RS}}\right)$. Therefore, when we assess the impact of PEEP based upon arterial oxygenation or compliance, we are assessing indirectly its effects upon alveolar volume. Our nearly exclusive focus on the extent to which oxygenation improves with PEEP is a matter of bedside expedience. Unfortunately, we seldom, if ever, state this association explicitly, and this may foster misunderstanding.

When delimited to normal and abnormally low conditions, FRC is directly proportional to $\mathrm{C}_{\mathrm{RS}}$ and inversely proportional to $\mathrm{P}_{\mathrm{aO}_{2}}$, relative to either $\mathrm{F}_{\mathrm{IO}_{2}}\left(\mathrm{P}_{\mathrm{aO}_{2}} / \mathrm{F}_{\mathrm{IO}_{2}}\right)$ or alveolar oxygen tension $\left(\mathrm{P}_{[\mathrm{a} / \mathrm{A}] \mathrm{O}_{2}}\right)$. The foundational studies on how PEEP impacts pulmonary mechanics and gas exchange in ARDS clearly demonstrated these relationships $>40$ y ago. ${ }^{1,2}$ Thus, it is the relationship between $\mathrm{P}_{\mathrm{aO}}, \mathrm{C}_{\mathrm{RS}}$, and FRC that lies at the heart of the question being debated in this paper.

\section{Pro Argument: PEEP Titration Should Be Based on Chest Mechanics}

Management of ARDS with PEEP and monitoring its effects by measuring chest mechanics have been inextricably linked since the seminal paper by Ashbaugh et $\mathrm{al}^{3}$ almost a half-century ago. In that report "total compliance" measured in a "dynamic state" was "strikingly" reduced; was found to be "extremely valuable in following the course of this particular illness"; and was related to both the underlying lesion (increased alveolar surface tension/alveolar collapse) and the salutary effects of PEEP on oxygenation. Decades later, one of the authors reminisced how, discussing over coffee the phenomenon they eventually called ARDS, they were struck by how various in-

Mr Kallet is affiliated with Respiratory Care Services, University of California, San Francisco, Department of Anesthesia at San Francisco General Hospital, San Francisco, California.

Mr Kallet presented a version of this paper at the 54th RESPIRATORY CARE Journal Conference, "Respiratory Care Controversies III," held June 5-6, 2015, in St Petersburg, Florida.

Mr Kallet has disclosed no conflicts of interest.

Correspondence: Richard H Kallet MSc RRT FAARC, Department of Anesthesia, University of California San Francisco at San Francisco General Hospital, NH:GA-2, 1001 Potrero Avenue, San Francisco, CA 94110.

DOI: $10.4187 /$ respcare.04657 sults produced "stiff lungs and marked difficulties with oxygenation."4

The early years of clinical research on PEEP found that when utilizing a tidal volume $\left(\mathrm{V}_{\mathrm{T}}\right)$ of 2-3 times normal (ie, $12-15 \mathrm{~mL} / \mathrm{kg}$ ), applying a PEEP of $5 \mathrm{~cm} \mathrm{H}_{2} \mathrm{O}$ was safe, ${ }^{5}$ PEEP levels between 7 and $10 \mathrm{~cm} \mathrm{H}_{2} \mathrm{O}$ often caused dramatic improvements in $\mathrm{P}_{\mathrm{aO}},{ }^{6}$ but levels of $10-13 \mathrm{~cm} \mathrm{H} \mathrm{H}_{2} \mathrm{O}$ also were associated with increased risk of systemic hypotension and barotrauma. ${ }^{7,8}$ In the early 1970 s, this led to a general impression that PEEP should only be applied between 5 and $15 \mathrm{~cm} \mathrm{H}_{2} \mathrm{O}$ in patients with ARDS. ${ }^{1,9}$ Since that time, it has been accepted practice that PEEP should be applied incrementally in steps of 3-5 $\mathrm{cm} \mathrm{H}_{2} \mathrm{O}$ and assessed by its effect upon hemodynamics, $\mathrm{C}_{\mathrm{RS}}$, and oxygenation. This was emphasized because of the tendency for PEEP to be applied indiscriminately and without forethought to its potential for causing adverse effects. ${ }^{10}$

\section{The Relationship Between PEEP, $\mathrm{C}_{\mathrm{RS}}$, FRC, and Oxygenation}

In clinical practice, assessing the mechanical effects of PEEP is done indirectly through the measurement of $C_{R S}$ by dividing the difference between end-inspiratory plateau pressure $\left(\mathrm{P}_{\mathrm{plat}}\right)$ and PEEP into $\mathrm{V}_{\mathrm{T}}$. Also referred to as chord compliance (ie, a line segment connecting 2 points on a curve), it assumes a linear relationship between pressure and volume as well as assuming that improvements in $\mathrm{C}_{\mathrm{RS}}$ primarily reflect changes in the intrinsic properties of lung tissue (ie, alveolar recruitment). ${ }^{11}$ The physiologic studies of PEEP in patients with various forms of acute respiratory failure (most of whom now would be recognized as having ARDS) clearly demonstrated a linear relationship between incremental increases in PEEP with improvements in FRC, dynamic and quasi-static $\mathrm{C}_{\mathrm{RS}}$, and oxygenation. ${ }^{1,2}$ Moreover, the adverse effects of PEEP on lung overdistention and hemodynamic compromise were clearly evident when $\mathrm{C}_{\mathrm{RS}}$ deteriorated as either PEEP or the size of the $\mathrm{V}_{\mathrm{T}}$ used with its application exceeded optimal settings (Fig. 1). 1,2,12,13

\section{Ventilator-Induced Lung Injury: Shifting Emphasis From Oxygenation to Monitoring Stress-Strain Relationships During PEEP and $V_{T}$ Titration in ARDS}

By the mid-1990s it was readily apparent that mechanical ventilation itself perpetuated lung injury. ${ }^{14-16} \mathrm{~A}$ famous study at that time raised the question of whether PEEP should be set according to oxygenation, by its impact on lung mechanics, or by chest computed tomography (CT) findings. ${ }^{17}$ These investigators found that ventilatorinduced lung injury (VILI) was largely dependent upon the unique mechanical properties of individual patients in 

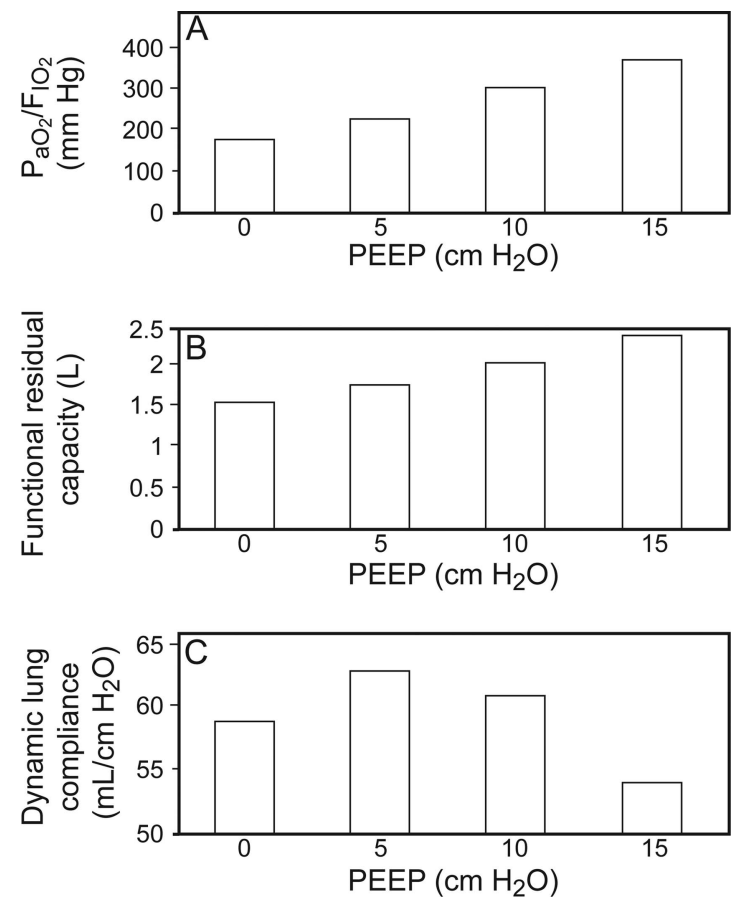

Fig. 1. The relationship between oxygenation $(A)$, functional residual capacity $(B)$, and dynamic lung compliance (C) as PEEP is titrated from 0 to $15 \mathrm{~cm} \mathrm{H}_{2} \mathrm{O}$. The study by Falke et al ${ }^{1}$ was the first to demonstrate that as PEEP is increased during tidal ventilation, there is dissociation between improvements in lung volume and oxygenation with excessive lung stress strain. These findings were the first clinical evidence indirectly suggesting the heterogeneous nature of lung injury in patients with acute respiratory failure. Data from Reference 1.

relation to their ventilator settings and that assessing oxygenation was merely a simple, cheap and repeatable method for adjusting PEEP at the bedside. They concluded that titrating PEEP upward based upon oxygenation is a reasonable first approach, but in those patients who have a poor oxygenation response, pulmonary mechanics must be brought into the assessment to limit the risk of VILI.

Utilizing chest CT scans to examine the spatial distribution of lung injury and its response to mechanical ventilation led to the concept that adults with ARDS possessed "baby lungs." 18 The traditional impression from chest radiographs that the lungs were globally edematous was in error. And in fact, in severe ARDS, between 200 and $500 \mathrm{~g}$ of lung tissue (the approximate lung size of a $5-6$-y-old child) was normally aerated. ${ }^{18}$ Given that the average weight of the adult lungs is approximately $840 \mathrm{~g}$ (range $370-1,850 \mathrm{~g}$ ), ${ }^{19}$ a reduced functional lung size amplifies $\mathrm{V}_{\mathrm{T}}$ by a factor of 1.7-4.2. Thus, a $\mathrm{V}_{\mathrm{T}}$ of $10-15 \mathrm{~mL} / \mathrm{kg}$ translates into a functional one ranging from between 17 and $26 \mathrm{~mL} / \mathrm{kg}$ to between 42 and $63 \mathrm{~mL} / \mathrm{kg}$, depending upon the amount of normally aerated lung tissue. In the classic preclinical studies of VILI, the $\mathrm{V}_{\mathrm{T}}$ used to produce severe lung injury was approximately
$40 \mathrm{~mL} / \mathrm{kg} .{ }^{14,20}$ Given the unique presentation of lung injury among individual patients possessing a wide range of lung mass, it is difficult to predict what combination of PEEP and $\mathrm{V}_{\mathrm{T}}$ would probably be safe without measuring chest mechanics. This represents the crux of the pro argument.

How VILI develops in patients with ARDS is even more complex because of the heterogeneous nature of lung injury. In a non-homogeneously injured lung, areas that are consolidated are exposed to stress (from compressive forces) but are not strained because they do not expand. In contrast, adjacent aerated tissue undergoes excessive strain and disproportionate increases in stress that induces an inflammatory cascade. ${ }^{21}$ Interestingly, there is evidence that for the same magnitude of strain, reducing its amplitude by increasing the baseline strain reduces alveolar epithelial injury. ${ }^{21,22}$ This implies that increasing PEEP but keeping $\mathrm{P}_{\text {plat }}$ constant would reduce VILI; this is consistent with the original preclinical studies ${ }^{14,20}$ and is the basis of the open lung ventilation strategy. ${ }^{23}$ As will be discussed below, adjusting PEEP to counter the effects of compressive and congestive atelectasis will also reduce shear injury from repetitive opening and closing of alveolar units during tidal ventilation. Finally, that a portion of the lungs in ARDS is normally aerated does not insinuate the absence of inflammation. Evidence has shown that all lung tissue has increased metabolism associated with inflammatory cell activity. ${ }^{24}$ This underscores the importance of limiting the effects of regional lung overdistention because it probably aggravates inflammation in areas of the lung that remain relatively normal.

\section{Setting PEEP According to Pressure-Volume Curves}

Utilization of pressure-volume (P-V) curves to set PEEP in ARDS according to the lower inflection point (LIP), also referred to as the zone of maximum curvature, was first introduced in 1979.25 Although only reported in abstract form, the average LIP in ARDS was $9 \pm 3.7 \mathrm{~cm} \mathrm{H}_{2} \mathrm{O}$ with a range of $8-18 \mathrm{~cm} \mathrm{H}_{2} \mathrm{O}$. Because LIP represents a zone of recruitment, an arbitrary $2 \mathrm{~cm} \mathrm{H}_{2} \mathrm{O}$ was added so that the inferred average PEEP requirement was $11 \mathrm{~cm} \mathrm{H}_{2} \mathrm{O}$. Lemaire et $\mathrm{al}^{25}$ originally believed that setting PEEP in this manner represented the best PEEP described by Suter et al. ${ }^{2}$ Setting PEEP and $\mathrm{V}_{\mathrm{T}}$ according to the P-V gained popularity at the same time that VILI became a predominant concern.

The open lung ventilation strategy was the first to incorporate P-V curves in setting PEEP above the LIP, and 2 randomized controlled trials were able to demonstrate a significant reduction in mortality and reduced duration of mechanical ventilation using open lung ventilation. ${ }^{26,27} \mathrm{An}$ additional aspect of setting the ventilator according to the $\mathrm{P}-\mathrm{V}$ curve is to limit $\mathrm{V}_{\mathrm{T}}$ so that $\mathrm{P}_{\text {plat }}$ is below the upper 


\section{PEEP Titration Based on Chest Mechanics in ARDS}

inflection point on the inflation limb, which is believed to signify decreased $C_{R S}$ from lung overdistention.

In an observational study, all subjects with ARDS had a surprisingly low upper inflection point (mean $26 \mathrm{~cm} \mathrm{H}_{2} \mathrm{O}$; range $18-40 \mathrm{~cm} \mathrm{H}_{2} \mathrm{O}$ ), and $>70 \%$ of subjects had a $\mathrm{P}_{\text {plat }}$ exceeding the upper inflection point despite being managed with moderate PEEP $\left(10 \pm 3 \mathrm{~cm} \mathrm{H}_{2} \mathrm{O}\right) .{ }^{28} \mathrm{~A}$ third randomized controlled trial of open lung ventilation used both the LIP and upper inflection point to set PEEP and $\mathrm{V}_{\mathrm{T}}$ and found that this strategy reduced pro-inflammatory mediator expression. ${ }^{29}$ In the control group $\left(\mathrm{V}_{\mathrm{T}}\right.$ of $11.1 \pm 1.9 \mathrm{~mL} / \mathrm{kg}$; low PEEP), the set PEEP was below the LIP $\left(6.5 \pm 1.7 \mathrm{~cm} \mathrm{H}_{2} \mathrm{O}\right.$ vs $13.6 \pm 3.9 \mathrm{~cm} \mathrm{H}_{2} \mathrm{O}$, respectively), and $\mathrm{P}_{\text {plat }}$ approximated the upper inflection point $\left(31 \pm 4.5 \mathrm{~cm} \mathrm{H}_{2} \mathrm{O}\right.$ vs $30.5 \pm 4.5 \mathrm{~cm} \mathrm{H}_{2} \mathrm{O}$, respectively). In contrast, the open lung ventilation group set PEEP above LIP $\left(14.8 \pm 2.7 \mathrm{~cm} \mathrm{H}_{2} \mathrm{O}\right.$ vs $12.6 \pm 2.8 \mathrm{~cm} \mathrm{H}_{2} \mathrm{O}$, respectively) with the set $\mathrm{V}_{\mathrm{T}}$ of $7.6 \pm 1.1 \mathrm{~mL} / \mathrm{kg}$ that yielded a $\mathrm{P}_{\text {plat }}$ below the upper inflection point $\left(24.6 \pm 2.4 \mathrm{~cm} \mathrm{H}_{2} \mathrm{O}\right.$ vs $31.7 \mathrm{~cm} \mathrm{H}_{2} \mathrm{O}$, respectively).

The evidence from both observational and randomized controlled trials clearly demonstrates that the open lung ventilation strategy, based on information provided by the inflation P-V curve, reduces the inflammatory cascade in ARDS and improves patient outcomes compared with traditional approaches. It can be argued that more precise mechanics information gleaned during open lung ventilation further refines ventilator adjustments according to the specific requirements of individual patients. Therefore, open lung ventilation may improve patient outcomes compared with the ARDSNet ${ }^{30}$ approach, which determines PEEP according to both $\mathrm{P}_{\mathrm{aO}_{2}}$ goals and $\mathrm{F}_{\mathrm{IO}_{2}}$ requirements and then adjusts $\mathrm{V}_{\mathrm{T}}$ to control any increases in $\mathrm{P}_{\text {plat }}$ above an arbitrarily set limit of $30 \mathrm{~cm} \mathrm{H}_{2} \mathrm{O}$.

\section{Application of PEEP Guided by Stress Index}

The traditional method of PEEP titration is modeled, more or less, on the seminal study by Suter et al, ${ }^{2}$ whereby relative improvements in oxygenation and $\mathrm{C}_{\mathrm{RS}}$ are balanced to minimize both alveolar overdistention and hemodynamic compromise. As mentioned above, the key to its interpretation is $\mathrm{V}_{\mathrm{T}}$ size. ${ }^{12}$ Regional lung overdistention in patients with ARDS, despite the use of a physiologic $\mathrm{V}_{\mathrm{T}}$ and $\mathrm{P}_{\text {plat }}<30 \mathrm{~cm} \mathrm{H}_{2} \mathrm{O}$, has been observed during positron emission tomography scans and is associated with increased pro-inflammatory mediator expression. ${ }^{31}$ This phenomenon also has been detected by measuring changes in intra- $\mathrm{V}_{\mathrm{T}}$ compliance $\left(\mathrm{C}_{\mathrm{SLICE}}\right)$. $^{32}$ The $\mathrm{C}_{\mathrm{SLICE}}$ method subdivides $\mathrm{V}_{\mathrm{T}}$ into 6 equal volume slices plotted against the concurrent change in airway pressure. This allows the inference of dynamic $C_{R S}$ during the course of $V_{T}$ delivery. Lung overdistention is detected by the position of at least some $\mathrm{V}_{\mathrm{T}}$ slices on a descending limb of the curve.

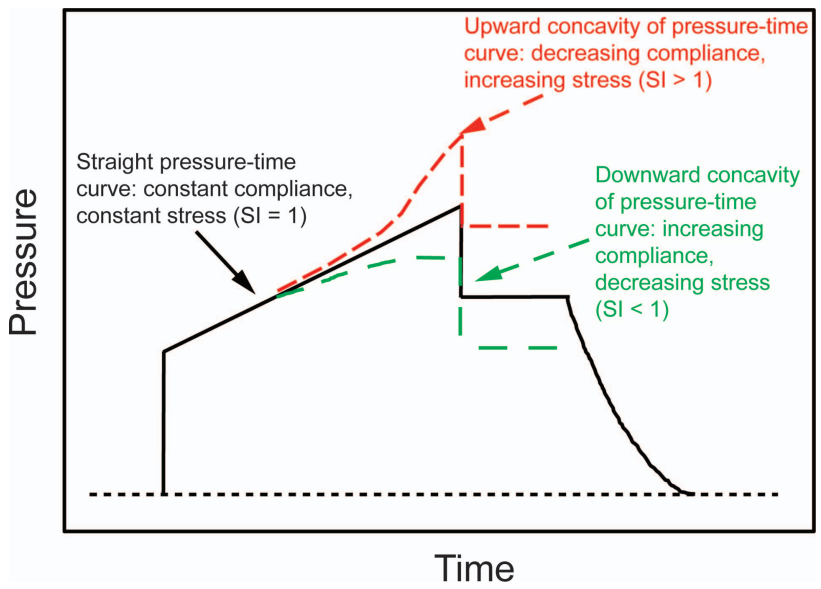

Fig. 2. Graphic representation of a dynamic airway pressure scalar during volume control ventilation with a constant inspiratory flow. The stress index $(\mathrm{SI})^{33}$ is derived from changes in the pressure slope throughout inspiration (following the initial pressure step primarily associated with flow resistance). Similar to the $\mathrm{C}_{\text {SLICE }}$ methodology, changes in the airway pressure at a constant rate of chest distention signify increasing, constant, or decreasing chest compliance.

A similar method examines the slope of airway pressure at 2 time points occurring during the early and late inspiratory phase and is referred to as the stress index (Fig. 2) ${ }^{33}$ Both techniques require volume control ventilation with a constant flow pattern so that alveolar volume and pressure increase at a constant rate. After the initial inspiratory pressure step associated with the flow resistance, the slope of airway pressure rise reflects changes in $\mathrm{C}_{\mathrm{RS}}$ (ie, the rate rise in alveolar pressure $=$ inspiratory flow rate/ $\mathrm{C}_{\mathrm{RS}}$ ). In animal models of ARDS, the stress index can detect both tidal recruitment and hyperinflation that was verified either by concurrent chest CT imaging ${ }^{34}$ or by pro-inflammatory mediator expression. ${ }^{33}$

In subjects with ARDS, incorporating stress index measurements detected tidal hyperinflation in subjects managed using the ARDSNet protocol, ${ }^{30}$ compared with those managed with similar $\mathrm{V}_{\mathrm{T}}$ but with PEEP adjusted to normalize stress index (rather than decreasing $\mathrm{V}_{\mathrm{T}}$ further). The stress index strategy resulted in a significant reduction in pro-inflammatory mediators. ${ }^{35}$ Another study ${ }^{36}$ found that subjects managed with the ARDSNet protocol ${ }^{30}$ also had tidal hyperinflation and higher pro-inflammatory mediator expression compared with those managed by stress index. This occurred despite a nearly identical $\mathrm{V}_{\mathrm{T}}$ and $\mathrm{P}_{\text {plat }}$ levels widely considered to be safe $\left(27.5 \pm 2.7 \mathrm{~cm} \mathrm{H}_{2} \mathrm{O}\right.$ vs $24.8 \pm 2.3 \mathrm{~cm} \mathrm{H}_{2} \mathrm{O}$, respectively, $P=.04$ ). Those managed using the ARDS Net protocol also had a significantly higher stress index $(1.14 \pm 0.09$ vs $1.06 \pm 0.09$, respectively, $P<.001)$.

Ultimately, using stress index to set PEEP or $\mathrm{V}_{\mathrm{T}}$ may be a particularly effective approach to managing ARDS when 


\section{PEEP Titration Based on Chest Mechanics in ARDS}

chest-wall compliance $\left(\mathrm{C}_{\mathrm{CW}}\right)$ is decreased, because $\mathrm{P}_{\text {plat }}$ will no longer be a reliable surrogate for lung stress. Under these circumstances, titrating PEEP and $\mathrm{V}_{\mathrm{T}}$ according to its impact on $\mathrm{P}_{\text {plat }}$ may result in unnecessary reductions in $\mathrm{V}_{\mathrm{T}}$, resulting in hypercapnia (which may adversely affect right heart function). ${ }^{37}$ In a recent animal model of ARDS with decreased $\mathrm{C}_{\mathrm{CW}}$ from abdominal restriction, a safe stress index (ie, approximately 1 in each group) could be achieved at the same PEEP level and higher $\mathrm{V}_{\mathrm{T}}$ $(7.3 \pm 0.7 \mathrm{~mL} / \mathrm{kg}$ vs $5.4 \pm 0.8 \mathrm{~mL} / \mathrm{kg})$ and higher $\mathrm{P}_{\text {plat }}$ ( $35 \pm 2 \mathrm{~cm} \mathrm{H}_{2} \mathrm{O}$ vs $30 \pm 1 \mathrm{~cm} \mathrm{H}_{2} \mathrm{O}$ ) with similar degrees of oxygenation and substantially less hypercarbia. ${ }^{38}$

\section{Utilizing Esophageal Manometry to Set PEEP}

Compressive forces generated by overlying edematous lung tissue and mediastinal structures as well as the abdominal and thoracic portions of the chest wall act to collapse the dorsal-caudal lung regions. Talmor et al ${ }^{39}$ proposed that, despite technical limitations, esophageal pressure could be used to set both PEEP and $\mathrm{V}_{\mathrm{T}}$ by estimating its effects on transpulmonary pressure at end-expiration and end-inspiration, respectively. In this schema, a negative end-expiratory transpulmonary pressure is interpreted as signifying alveolar collapse. Therefore, PEEP is titrated to maintain an end-expiratory transpulmonary pressure range between 0 and $10 \mathrm{~cm} \mathrm{H}_{2} \mathrm{O}$ based upon $\mathrm{F}_{\mathrm{IO}_{2}}$ and $\mathrm{P}_{\mathrm{aO}_{2}}$ goals similar to the ARDS Net PEEP/F $\mathrm{IO}_{2}$ table. ${ }^{30}$ For example, when $\mathrm{F}_{\mathrm{IO}_{2}}$ requirements were $\geq 0.90$, transpulmonary pressure was kept at $10 \mathrm{~cm} \mathrm{H}_{2} \mathrm{O}$, and when $\mathrm{F}_{\mathrm{IO}_{2}}$ requirements were $<0.50$, transpulmonary pressure was maintained at $0 \mathrm{~cm} \mathrm{H}_{2} \mathrm{O}$ (ie, signifying a balance between intra-alveolar and pleural pressure assumed to maintain alveolar stability at end-expiration). Likewise, $\mathrm{V}_{\mathrm{T}}$ is titrated to maintain an end-inspiratory transpulmonary pressure of $<25 \mathrm{~cm} \mathrm{H}_{2} \mathrm{O}$. In consequence, measuring transpulmonary pressure allows both PEEP and $\mathrm{V}_{\mathrm{T}}$ to be adjusted according to individual disturbances in lung compliance and $\mathrm{C}_{\mathrm{CW}}$ rather than relying upon the less precise measurement of $\mathrm{C}_{\mathrm{RS}}$.

In their initial pilot study, Talmor et al ${ }^{39}$ reported that both oxygenation and $\mathrm{C}_{\mathrm{RS}}$ improved markedly compared with the control group that was managed with the original ARDSNet PEEP/F $\mathrm{IO}_{2}$ table. ${ }^{30}$ Higher levels of PEEP were required in the transpulmonary pressure-managed group compared with the control group $(17 \pm 6$ vs $10 \pm 4$, respectively, $P<.01)$, but $\mathrm{V}_{\mathrm{T}}$ was similar $(7.1 \pm 1.3 \mathrm{~mL}$ vs $6.8 \pm 1.0 \mathrm{~mL}$, respectively, $P=.31$ ). After adjusting for illness severity, 28-d mortality risk also was lower in the transpulmonary pressure study arm (relative risk [95\% CI]: $0.46[0.19-1], P=.049)$. This suggests that the contributory mortality risk from VILI was probably reduced by the protective effects of higher PEEP on ameliorating sheer injury. Furthermore, it suggests that titrat- ing $\mathrm{V}_{\mathrm{T}}$ according to end-inspiratory transpulmonary pressure rather than $\mathrm{P}_{\text {plat }}$ may prevent unnecessary reductions in $\mathrm{V}_{\mathrm{T}}$. These results from a single-center study are currently being tested in a larger phase 3 multi-center study. 40

In summary, the evidence points to the fact that in heterogeneous lung disease, there is an uncoupling of the effects of PEEP on oxygenation from its effects on stressstrain relationships and the perpetuation of lung injury, particularly in patients with established ARDS. Moreover, there is sobering evidence suggesting that PEEP influences mortality based upon the severity of lung injury, such that using higher levels of PEEP on those with mild lung injury paradoxically increases mortality risk. ${ }^{41}$ Readily available clinical measurements of lung mechanics, such as quasi-static $\mathrm{C}_{\mathrm{RS}}$, are a crucial component for the safe application of PEEP and have been recognized as such for the past half-century. Further technological developments (eg, the clinical availability of automated measurements of P-V curves, stress index, transpulmonary pressure, and FRC) allowing more sophisticated bedside measurements of chest mechanics ultimately may be shown to improve patient outcomes further than can be appreciated at this time.

\section{Con Argument: PEEP Titration Should Not Be Based on Chest Mechanics}

As described above in the pro argument, since the early 1970s, accepted practice has been that PEEP should be used within a relatively narrow range between 5 and $15 \mathrm{~cm} \mathrm{H}_{2} \mathrm{O}$. Therefore, it is of interest to examine whether recommendations based upon clinical evidence from $>40 y$ ago remain pertinent today. The con argument frames the question under debate as follows: Is it usually necessary, from a practical standpoint, that PEEP be titrated according to changes in chest mechanics rather than oxygenation? It is important to emphasize the specific context of how the con argument is structured: usually and practical. The argument against the reliance upon pulmonary mechanics to guide how PEEP is set can be summarized as follows. (1) Historically, the majority of patients with ARDS or other forms of severe respiratory failure have required mean PEEP levels that fall within a very narrow range (9-13 $\left.\mathrm{cm} \mathrm{H}_{2} \mathrm{O}\right){ }^{7,25,42}$ (2) All clinical measurements of chest mechanics have varying degrees of imprecision and/or technical difficulty that limit that their usefulness in selecting PEEP in patients with moderate to severe ARDS. (3) What we perceive to be lung recruitment when applying PEEP, particularly in ARDS, may not necessarily comport with the actual physiology responsible for the improvement in oxygenation. ${ }^{43-45}$ Hence, changes in chest mechanics may not add to our understanding or decision making at the bedside. 


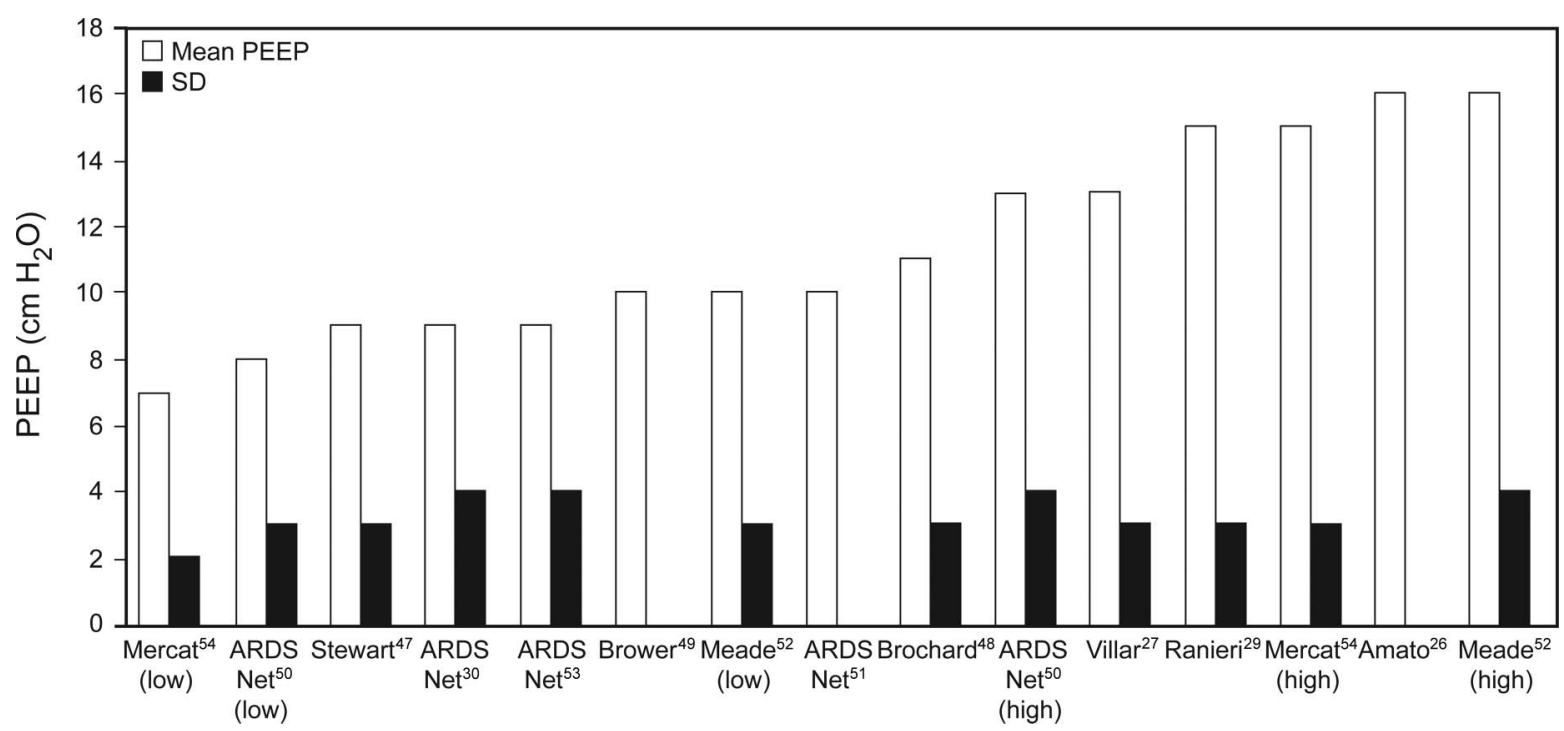

Fig. 3. Mean \pm SD PEEP requirements from randomized clinical trials of lung-protective ventilation whereby PEEP and $F_{1 O_{2}}$ were titrated to maintain $\mathrm{P}_{\mathrm{aO}_{2}}<100 \mathrm{~mm} \mathrm{Hg}$. In studies where both treatment arms used a physiologic $\mathrm{V}_{\mathrm{T}}$, the descriptors high and low are used to identify assignment to either lower or higher PEEP management. In studies that compared lung protective ventilation to traditional mechanical ventilation, only PEEP data from the lung-protective cohort are displayed.

It is important to emphasize that the con argument is not meant to dissuade clinicians from measuring and monitoring chest mechanics in patients with respiratory failure. Rather, the argument merely attempts to point out the ambiguities and limitations of doing so in the context of clinical pragmatism.

Several lines of clinical evidence regarding PEEP accumulated over the past $40 \mathrm{y}$ provide interesting insights as to the ranges of PEEP most patients require for clinical management. This evidence should be interpreted within the context of a widely accepted management strategy based not on optimizing oxygenation but rather biased toward a least PEEP strategy: the lowest level of PEEP assuring an adequate $\mathrm{P}_{\mathrm{aO}_{2}}(70 \mathrm{~mm} \mathrm{Hg})$ on a non-toxic $\mathrm{F}_{\mathrm{IO}_{2}}$ $(\leq 0.60$ or 0.70$) .{ }^{1,46}$ Most major clinical trials involving PEEP titration during lung-protective ventilation have incorporated some version of this approach regardless of whether a lower or higher PEEP strategy was being tested. ${ }^{26,30,47-54}$ In essence, these studies found that in early ARDS, mean PEEP levels needed to achieve clinically reasonable $\mathrm{P}_{\mathrm{aO}_{2}}$ and $\mathrm{F}_{\mathrm{IO}_{2}}$ targets was only 7-16 $\mathrm{cm} \mathrm{H}_{2} \mathrm{O}$. In the majority of studies, mean PEEP was $<15 \mathrm{~cm} \mathrm{H}_{2} \mathrm{O}$ and, in most cases, was associated with a relatively narrow distribution (Fig. 3).

\section{PEEP and Its Relationship to Quasi-Static Compliance and FRC}

As mentioned above, the effects of PEEP are assessed clinically by measuring $\mathrm{C}_{\mathrm{RS}}$, yet this assumes that (1) a linear relationship exists between pressure and volume and
(2) changes in $C_{R S}$ necessarily reflect changes in the intrinsic properties of lung tissue. ${ }^{11}$ This is a precarious assumption in patients with pulmonary disease for several reasons. Foremost is that the lungs and chest wall (thoracic and abdominal components) are elastic structures in series. Therefore, without measuring esophageal pressure as a surrogate for pleural pressure, it is very difficult to differentiate whether improvements or deterioration in pulmonary function are due to changes in the elastic properties of the lung parenchyma, chest wall, or some combination of both.

Moreover, determining whether PEEP has actually recruited alveolar tissue and/or improved aeration requires the measurement of what has been termed FRC compliance: $\triangle$ FRC/ $\triangle$ PEEP. ${ }^{55}$ The uncertainty of whether changes in $C_{R S}$ reflect recruitment was elegantly demonstrated by Katz et al ${ }^{55}$ Stepwise increases in PEEP between 3 and $18 \mathrm{~cm} \mathrm{H}_{2} \mathrm{O}$ returned FRC to normal predicted values while the corresponding FRC compliance steadily improved. In contrast, $\mathrm{C}_{\mathrm{RS}}$ was consistently lower than FRC compliance and paradoxically deteriorated at the highest level of PEEP despite restoration of FRC to normal (Fig. 4). This phenomenon might be explained by their use of a large $\mathrm{V}_{\mathrm{T}}$ $(\sim 700 \mathrm{~mL})$ because changes in $\mathrm{C}_{\mathrm{RS}}$ during PEEP titration are largely determined by $\mathrm{V}_{\mathrm{T}}$ chosen during measurements (Fig. 5). ${ }^{12}$ Moreover, approximately $90 \%$ of the increase in FRC occurred within a few breaths and was predicted by baseline $\mathrm{C}_{\mathrm{RS}}$. This strongly suggests that the majority of FRC change resulted from enhanced expansion and stabilization of patent alveoli. Only about $10 \%$ of FRC occurred in a slow compartment that was attributable to re- 


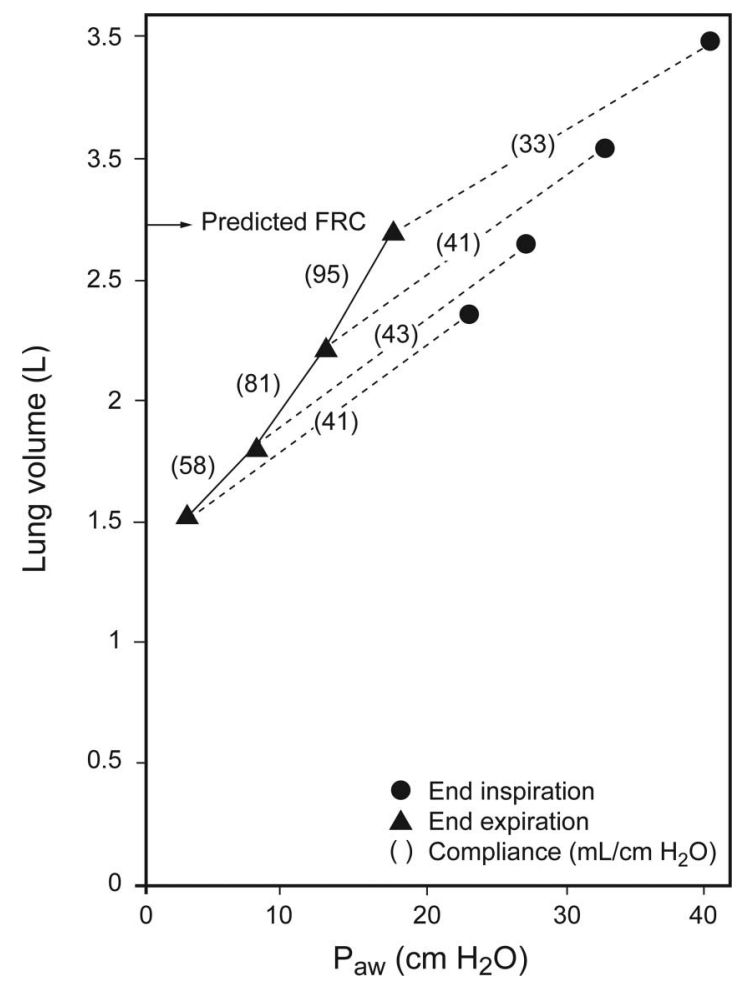

Fig. 4. Differences between functional residual capacity compliance (FRC) (triangles) and respiratory system compliance (circles) as PEEP is increased. $P_{\text {aw }}=$ airway pressure. See text for details. From Reference 55, with permission.

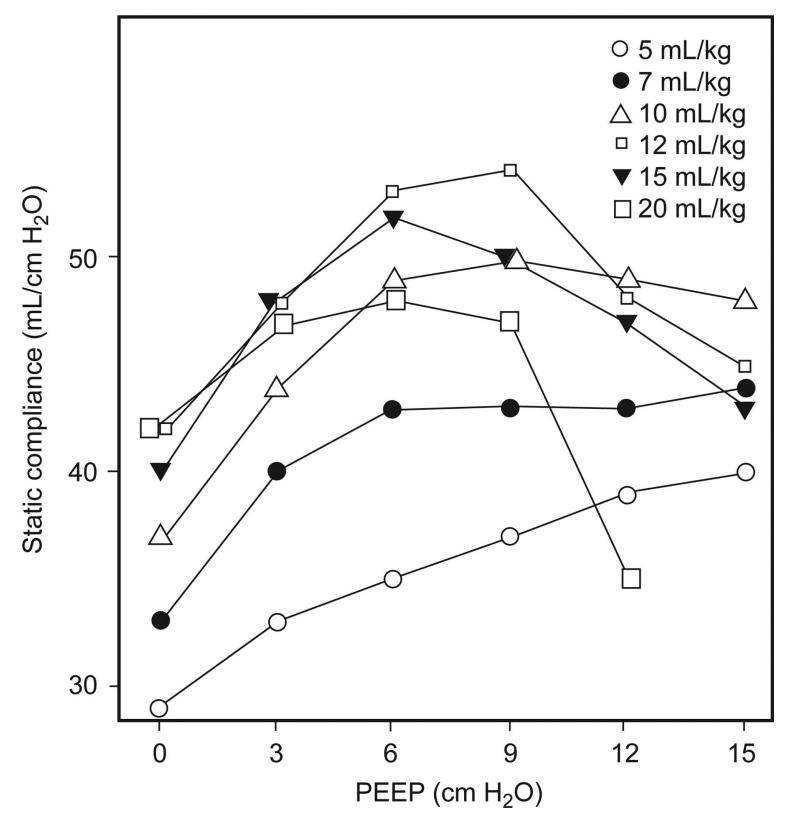

Fig. 5. The effects of $V_{T}$ on respiratory system compliance during PEEP titration. Note that as PEEP increased when physiologic $V_{T}$ of either 5 (white circles) or $7 \mathrm{~mL} / \mathrm{kg}$ (black circles) was used, compliance continued to increase even at a PEEP of $15 \mathrm{~cm} \mathrm{H}_{2} \mathrm{O}$. In contrast, compliance decreased as PEEP was increased and a larger $\mathrm{V}_{\mathrm{T}}$ was used. From Reference 12, with permission. cruitment. The study was not designed to account for the commonly observed phenomenon of steady improvement in $\mathrm{C}_{\mathrm{RS}}$ and oxygenation over a period of hours, which probably reflects the gradual recruitment of lung tissue afflicted by the presence of sticky atelectasis hypothesized by others. ${ }^{56}$ This evidence underscores the practical limitations of assessing the short-term effects of PEEP by monitoring $\mathrm{C}_{\mathrm{RS}}$ at the bedside.

\section{Application of PEEP Guided by Stress Index}

The clinical applicability of stress index is limited by requiring passive ventilation to ensure accuracy and also physiologically because it assumes that the resistive and viscoelastic properties of the chest remain constant throughout the breath. In addition, it requires sophisticated software capable of identifying flow transients as well as data points corresponding to the constant part of mean inspiratory flow, which then are fitted to the power equation that determines the pressure slope over time. ${ }^{33}$ Currently, this technology is not commercially available, and its clinical utility, although intriguing, is partly limited by the experimental protocols used to study it.

For example, Grasso et $\mathrm{al}^{35}$ reported that during lungprotective ventilation, PEEP titrated according to stress index compared with the ARDSNet ${ }^{30} \mathrm{PEEP} / \mathrm{F}_{\mathrm{IO}_{2}}$ tables resulted in similar oxygenation at significantly lower PEEP, lower pro-inflammatory mediator expression, and higher $\mathrm{C}_{\mathrm{RS}}$. Interestingly, $\mathrm{P}_{\text {plat }}$ was not reported, which is crucial, because the ARDS Net ${ }^{30}$ protocol mandates a reduction in $\mathrm{V}_{\mathrm{T}}$ to limit alveolar stress when higher levels of PEEP are required. Rather, PEEP was titrated downward only in the stress index group. This was necessary to establish the validity of stress index and demonstrate its potential as an alternative strategy, particularly for right heart-protective ventilation. ${ }^{37}$ Nonetheless, Huang et $a{ }^{57}$ reported that similar PEEP levels were indicated regardless of whether PEEP was set according to stress index, oxygenation, or LIP $\left(15.1 \pm 1.8,14.5 \pm 2.9\right.$, and $11.3 \pm 2.5 \mathrm{~cm} \mathrm{H}_{2} \mathrm{O}$, respectively).

Moreover, it is now generally recognized that significant lung injury can occur despite a physiologic $\mathrm{V}_{\mathrm{T}}$ of 6-7 mL/kg if it results in $\mathrm{P}_{\text {plat }}>25 \mathrm{~cm} \mathrm{H}_{2} \mathrm{O} .{ }^{36}$ Most recently, a post hoc analysis of data from $>3,500$ subjects in 9 major randomized controlled trials of lung-protective ventilation strongly suggests that keeping the elastic driving pressure $\left(\mathrm{P}_{\text {plat }}\right.$-PEEP) $\leq 15 \mathrm{~cm} \mathrm{H}_{2} \mathrm{O}$ is the most robust predictor of outcomes in ARDS. ${ }^{58}$ Therefore, sophisticated measurements of tidal stress are probably unnecessary, and simply adjusting $\mathrm{V}_{\mathrm{T}}$ to maintain a $\mathrm{P}_{\text {plat }} \leq 25 \mathrm{~cm} \mathrm{H}_{2} \mathrm{O}$ or $\mathrm{P}_{\text {plat }}-\mathrm{PEEP} \leq 15 \mathrm{~cm} \mathrm{H}_{2} \mathrm{O}$ may produce an effective margin of safety, particularly when higher PEEP is indicated. 




Fig. 6. Frequency distribution of the lower inflection point in subjects with ARDS. See text for details. From Reference 61.

\section{Setting PEEP According to Pressure-Volume Curves}

As mentioned above, Lemaire et al ${ }^{25}$ originally believed that setting PEEP according to the LIP represented the best PEEP described by Suter et al. ${ }^{2}$ However, data analyzed from a subsequent study comparing these strategies shows that LIP-determined PEEP requirements are higher than those needed to maximize $\mathrm{C}_{\mathrm{RS}}$ during lung-protective ventilation $\left(14.2 \pm 4.8 \mathrm{~cm} \mathrm{H}_{2} \mathrm{O}\right.$ vs $10.3 \pm 4.8 \mathrm{~cm} \mathrm{H}_{2} \mathrm{O}$, respectively, $P=.001$ ) and that only a moderate correspondence exists between the 2 techniques $(\mathrm{r}=0.59$, $P=.007) .{ }^{59}$ In addition, the best PEEP technique was more reliable and had fewer problems associated with inter-rater reliability ${ }^{59}$ (another prominent issue stymieing widespread embracement of this technique in clinical practice). ${ }^{60}$

At least 16 other studies have reported individual values of LIP in early ARDS. These data (approximately 200 individual LIP measurements) were subsequently constructed into a frequency distribution curve, which showed that $>50 \%$ of subjects with ARDS had an LIP $\leq 10 \mathrm{~cm} \mathrm{H}_{2} \mathrm{O}$, $84 \%$ had an LIP $<15 \mathrm{~cm} \mathrm{H}_{2} \mathrm{O}$, and only $5 \%$ had an LIP $>20 \mathrm{~cm} \mathrm{H}_{2} \mathrm{O}$ (Fig. 6). ${ }^{61}$ The mean \pm SD LIP of these measurements was $11 \pm 5 \mathrm{~cm} \mathrm{H}_{2} \mathrm{O}$. The review also found an additional 6 studies wherein only mean data were reported with similar results $\left(8-11 \mathrm{~cm} \mathrm{H}_{2} \mathrm{O}\right){ }^{61}$ These data reinforce the viewpoint that most patients with ARDS generally require only moderate levels of PEEP in a range similar to those reported in major prospective clinical trials where PEEP was titrated according to an oxygenationbased least PEEP strategy.

As the P-V curve was subjected to more intense investigation, numerous ambiguities emerged that further damped enthusiasm for its use in setting PEEP. First, mathematical modeling suggests that LIP encompasses both the force necessary to overcome superimposed hydrostatic pressure of overlying lung tissue and the threshold opening pressure of collapsed air spaces, implying that LIP represents the beginning of significant lung recruitment rather than the optimal pressure for recruitment. ${ }^{62}$ This was confirmed by other studies showing that PEEP set $7-9 \mathrm{~cm} \mathrm{H}_{2} \mathrm{O}$ above the LIP either continued to induce lung recruitment and improve oxygenation ${ }^{63}$ or was necessary to prevent progressive lung de-recruitment. ${ }^{64}$ In fact, preclinical and clinical studies both suggest that lung recruitment occurs continuously along the inflation limb of the P-V curve. ${ }^{65,66}$ More importantly, patients without evidence of an LIP respond to applied PEEP of $10-15 \mathrm{~cm} \mathrm{H}_{2} \mathrm{O}$ with improved oxygenation and evidence of lung recruitment. ${ }^{63,67}$ Interpreting LIP also can be misleading because it may represent changes in $\mathrm{C}_{\mathrm{CW}}$; setting PEEP according to LIP in these situations does not appear to improve oxygenation. ${ }^{68}$ In addition, when the P-V curve is constructed from ambient pressure, LIP may merely reflect the force necessary to overcome intrinsic PEEP from portions of the lung with prolonged time constants. ${ }^{69,70}$

Setting PEEP above LIP neither attenuates lung injury nor improves survival in animal models of ARDS, despite clear improvements in oxygenation and lung mechanics. ${ }^{71}$ Regarding amelioration of VILI (by reducing sheer stress from repetitive collapse-recruitment), setting PEEP according to the LIP paradoxically causes regional lung overdistention $^{42,72}$ and decreased intra- $\mathrm{V}_{\mathrm{T}}$ compliance (a marker of overdistention). ${ }^{73}$ Moreover, evidence that recruitment occurs throughout the inflation limb of the P-V logically negates the idea that setting PEEP at some point beyond the LIP can completely prevent sheer injury from occurring.

Small airway collapse and atelectasis represent expiratory phenomena, and the pressure required to recruit col- 


\section{PEEP Titration Based on Chest Mechanics in ARDS}

lapsed small airways and alveoli generally is greater than the pressure needed to prevent their collapse (at least under conditions of normal $\mathrm{C}_{\mathrm{CW}}$ ). Thus, the focus has shifted toward setting PEEP according to the deflation limb of the $\mathrm{P}-\mathrm{V}$ curve. Under normal physiologic conditions, deflation below FRC often produces an inflection point representing small airway closure. ${ }^{74}$ However, deflation and de-recruitment do not occur in parallel, so that deflation does not necessarily represent de-recruitment. ${ }^{66}$

$\mathrm{P}-\mathrm{V}$ curve modeling suggests that when PEEP is set from points on the deflation limb, the maximum slope of tidal compliance occurs at a PEEP of $16 \mathrm{~cm} \mathrm{H}_{2} \mathrm{O} .{ }^{75}$ This is below the point of maximum curvature, which is thought to represent where alveolar de-recruitment commences during deflation. ${ }^{76,77}$ Mean values of the point of maximum curvature have been found to exceed LIP by approximately 6-10 $\mathrm{cm} \mathrm{H}_{2} \mathrm{O} .{ }^{78,79}$ Under static conditions (during construction of the P-V curve), the point of maximum curvature has been characterized by higher levels of normally aerated lung tissue and less non-aerated lung tissue, whereas loss of aeration and de-recruitment (as assessed by CT scan) only becomes apparent below the point of maximum curvature. ${ }^{76}$ However, when PEEP was set according to the point of maximum curvature, subsequent tidal ventilation at $6 \mathrm{~mL} / \mathrm{kg}$ was associated with significant increases in $\mathrm{P}_{\text {plat }}$, decreased $\mathrm{C}_{\mathrm{RS}}$, increased $\mathrm{P}_{\mathrm{aCO}}$, and increases in hyperinflated lung tissue, which was associated with point of maximum curvature greatly exceeding LIP on the inflation limb $\left(25 \mathrm{~cm} \mathrm{H}_{2} \mathrm{O}\right.$ vs $15 \mathrm{~cm} \mathrm{H}_{2} \mathrm{O}$, respectively). ${ }^{77}$

The P-V curve is a global representation of the quasistatic elastic properties of the lungs and chest wall, with the steepest slopes signifying higher $\mathrm{C}_{\mathrm{RS}}$ and flatter portions lower $\mathrm{C}_{\mathrm{RS}}$. By extension, the flatter, upper portions of both the inflation and deflation limbs of the P-V curve are probably associated with increased probability of hyperinflation and increased risk of stretch-related injury (Fig. 7A). It would appear more prudent, therefore, that tidal ventilation occurs on the steeper portion of the deflation limb, where $\mathrm{C}_{\mathrm{RS}}$ is higher despite the fact that it has been associated with some degree of de-recruitment. It is therefore interesting that Albaceita et $\mathrm{al}^{76}$ suggested that just translating the LIP onto the deflation limb would greatly decrease the amount of non-aerated and poorly aerated lung tissue. This is readily apparent from the P-V curve (Fig. 7B) from one of their study subjects. ${ }^{77}$ As implied by the investigators, a $\mathrm{P}-\mathrm{V}$ curve is repeated (to obtain full recruitment), and then PEEP is set according to LIP. In this case, extending a perpendicular line upward from the LIP to the corresponding position on the deflation limb would have increased end-expiratory lung volume by approximately $400 \mathrm{~mL}$.

To place this strategy into a relevant context, when measured in patients with ARDS, mean FRC varies widely from 1.8 to $0.6 \mathrm{~L} .{ }^{78}$ This suggests that such an approach,
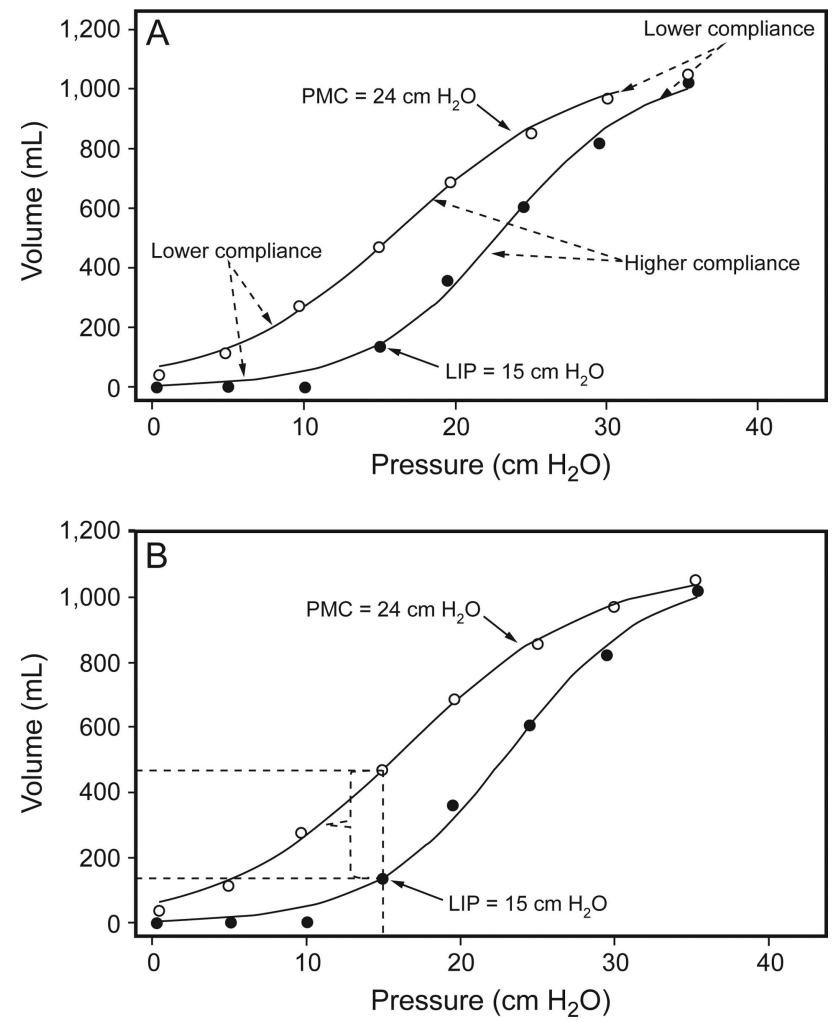

Fig. 7. Static pressure-volume curve from a patient with ARDS showing the lower inflection point (LIP) on the inflation limb signifying the beginning of significant lung recruitment and the point of maximum curvature (PMC) on the deflation limb that is believed to represent the beginning of de-recruitment (A). Steeper portions of curve on each limb represent higher compliance, whereas flatter portions signify lower compliance. Panel B illustrates the impact of setting PEEP according to the LIP (following a recruitment maneuver) on end-expiratory lung volume. This has been proposed as an alternative method of adjusting PEEP that may reduce shear stress while reducing the risk of stretch-related injury compared with setting PEEP according to the PMC. See text for details. From Reference 77, with permission.

although perhaps suboptimal, would probably induce substantial improvement in gas exchange and alveolar stability. More importantly, what may be optimal in terms of lung aeration and reduction of shear injury probably comes with extraordinary costs that may negatively impact patient outcomes. For example, cor pulmonale, a common feature of severe ARDS, is caused by chronic, excessive right ventricular afterload that is associated with significantly higher mortality. ${ }^{79,80}$ And, as noted above, minimizing de-recruitment inevitably causes some degree of regional lung overdistention, increasing the likelihood of stretch-related injury. Therefore, setting PEEP levels according to the point of maximum curvature may present an unacceptable risk to patients with ARDS.

Several studies have examined a decremental PEEP strategy that derives from the concept of setting PEEP according to the deflation limb of the P-V curve. ${ }^{81-86}$ Although 


\section{PEEP Titration Based on Chest Mechanics in ARDS}

this approach is based upon the pulmonary mechanics, the practical application is essentially the same as the ARDSNet studies in that PEEP is titrated according to oxygenation efficiency. ${ }^{30,50}$ There are several permutations to the decremental PEEP strategy with varying criteria of what signifies the de-recruitment threshold. But the approach described by Girgis et al ${ }^{82}$ serves as an appropriate model. A recruitment maneuver is performed using a sustained, maximal alveolar pressure of $40 \mathrm{~cm} \mathrm{H}_{2} \mathrm{O}$ for $40 \mathrm{~s}$. Lung-protective ventilation then resumes from $20 \mathrm{~cm} \mathrm{H}_{2} \mathrm{O}$ PEEP. Before decreasing PEEP, $\mathrm{F}_{\mathrm{IO}_{2}}$ is titrated to achieve an $\mathrm{S}_{\mathrm{pO}_{2}}$ of $90-94 \%$, so that any de-recruitment is more readily apparent. PEEP is then reduced $2 \mathrm{~cm} \mathrm{H}_{2} \mathrm{O}$ every 2-5 min until $\mathrm{S}_{\mathrm{pO}_{2}}$ is $<90 \%$. Thus, the PEEP just above the desaturation point is considered optimal PEEP. Another recruitment maneuver is done to reestablish FRC before returning PEEP to the optimal level.

Interestingly, in many studies, the mean optimal PEEP level established by a recruitment maneuver-decremental PEEP strategy was only $12 \mathrm{~cm} \mathrm{H}_{2} \mathrm{O}, 84,85$ or the strategy only reduced PEEP modestly compared with baseline (ie, from $\sim 12$ to $9 \mathrm{~cm} \mathrm{H}_{2} \mathrm{O}$ ). ${ }^{82}$ A study comparing the recruitment maneuver-decremental PEEP method to the ARDSNet PEEP- $\mathrm{F}_{\mathrm{IO}_{2}}$ table ${ }^{30}$ found that mean PEEP requirements were virtually indistinguishable $\left(\sim 10 \mathrm{~cm} \mathrm{H}_{2} \mathrm{O}\right) .{ }^{83}$ Only Borges et al ${ }^{81}$ reported a substantially higher optimal PEEP level $\left(20 \mathrm{~cm} \mathrm{H}_{2} \mathrm{O}\right)$, which may have resulted from more stringent criteria used to demarcate optimal PEEP.

\section{The Role of Esophageal Manometry in Setting PEEP}

One of the rationales for setting PEEP has been prevention of tidal collapse and subsequent recruitment believed to induce shear injury (particularly in the dependent lung regions). Although controversial in terms of physiology, the issue of superimposed hydrostatic pressure causing dependent lung collapse and hypoxemia does inform the current debate. As mentioned above, Talmor et $\mathrm{al}^{39}$ reported substantially higher PEEP levels at $72 \mathrm{~h}$ in the esophageal pressure-managed treatment arm. However, the resulting $\mathrm{P}_{\mathrm{aO}}$ exceeded satisfactory levels in both arms $(124 \pm 44 \mathrm{~mm} \mathrm{Hg}$ vs $101 \pm 33 \mathrm{~mm} \mathrm{Hg}$ ) and was achieved at a non-toxic $\mathrm{F}_{\mathrm{IO}_{2}}(<0.60)$. From a practical standpoint, these results raise the question of whether this technique is necessary in managing most cases of ARDS.

Although placement of an esophageal balloon is relatively easy, its interpretation is an acquired skill that requires more experience than one would suppose at first blush. Esophageal manometry has much to recommend it in managing ARDS complicated by morbid obesity, anasarca, or abdominal compartment syndrome, yet there remain nettlesome practical considerations because (like all sophisticated measurements and therapies) this technique is not something that can be reached for infrequently. To be both practical and effective, esophageal manometry requires an institutional commitment to training and maintaining skill levels (for a substantial number of practitioners) to prevent management errors from variability in technique or interpretation. This may limit its appeal for many hospitals compared with other less intrusive and less sophisticated techniques.

\section{Dead-Space Fraction and Optimal PEEP}

Forty years ago, Suter et $\mathrm{al}^{2}$ demonstrated the utility of measuring dead-space fraction $\left(\mathrm{V}_{\mathrm{D}} / \mathrm{V}_{\mathrm{T}}\right)$ to aid in determining optimal PEEP. Because $\mathrm{CO}_{2}$ is highly diffusible across tissue membranes (relative to oxygen), dead-space measurements are perfusion-sensitive and therefore readily capable of detecting recruitment or de-recruitment before changes in either oxygenation or $\mathrm{C}_{\mathrm{RS}}$ become apparent. ${ }^{87}$ In a recruitment maneuver-decremental PEEP trial, the best PEEP (defined by best $C_{R S}$ ) was compared with transpulmonary pressure. ${ }^{86}$ The best PEEP was $10 \mathrm{~cm} \mathrm{H}_{2} \mathrm{O}$, which corresponded to the best lung compliance and the lowest $\mathrm{V}_{\mathrm{D}} / \mathrm{V}_{\mathrm{T}}$. These results are consistent with preclinical and clinical studies of recruitment maneuver-decremental PEEP strategies on lung recruitment/de-recruitment. In an ARDS model, Tusman et al ${ }^{88}$ reported that $\mathrm{V}_{\mathrm{D}} / \mathrm{V}_{\mathrm{T}}$ had a high sensitivity and specificity for detecting lung collapse. In subjects undergoing general anesthesia, the optimal PEEP also was $10 \mathrm{~cm} \mathrm{H}_{2} \mathrm{O}$, which corresponded with the lowest $\mathrm{V}_{\mathrm{D}} / \mathrm{V}_{\mathrm{T}}$ and the maximum amount of effectively expanded alveoli. ${ }^{89}$ In another recruitment maneuver-decremental PEEP study, Fengmei et al ${ }^{85}$ also demonstrated that the lowest $\mathrm{V}_{\mathrm{D}} / \mathrm{V}_{\mathrm{T}}$ was found at a PEEP of $12 \mathrm{~cm} \mathrm{H}_{2} \mathrm{O}$ (just above the PEEP level where noticeable deterioration in oxygenation occurred) and was associated with both near-maximal $\mathrm{C}_{\mathrm{RS}}$ and reduced mortality.

\section{Uncertainty Regarding the Notion of Recruitment and De-Recruitment in ARDS}

Finally, from a purely philosophical-scientific standpoint, there is significant ambiguity in the phenomena we label as recruitment and de-recruitment. ${ }^{43-45}$ Very briefly, much of the argument for setting PEEP to prevent VILI is based upon several assumptions. First is that increased lung weight from edema compresses the dorsal-caudal lung, necessarily resulting in sheer stress from repetitive opening and closing of terminal air spaces during tidal ventilation. This assumption underlies the interpretation of the LIP in P-V curves as well the interpretation of CT scan imaging of the chest. What accounts for hysteresis (ie, the separation of the inflation and deflation limbs of the P-V curve) are primarily interactions at the air-liquid interface. ${ }^{60}$ However, the same physical properties are in play for any gas-liquid interface in the lungs during inflation. 


\section{PEEP Titration Based on Chest Mechanics in ARDS}

This was confirmed by Martynowitz et al, ${ }^{43,44}$ who discovered that what is identified as recruitment-de-recruitment actually appears to be the displacement of liquid and foam by the passage of gases in the peripheral air spaces during inflation and deflation. Moreover, the lungs, which by radiological and mechanical measurements appear and behave as if they are collapsed, when measured by tissue markers are actually flooded.

Second, the gray scale on CT chest images (upon which much of the evidence for recruitment and de-recruitment is based) cannot differentiate whether alveoli in a region of interest are atelectatic or flooded. Because CT imaging does not provide information on the actual state of lung tissue, assumptions about regional alveolar size or stress are essentially conjecture (ie, one would need to know a priori that the water content of alveoli was distributed homogeneously in order to infer whether recruitment or de-recruitment is actually being observed). For example, an increasing gray scale on CT imaging down the vertical height of the lung could indicate increased lung compression from superimposed hydrostatic pressure of the overlying edematous lung or consolidated lung tissue filled or partially filled with alveolar edema (or some combination thereof). Increasing aeration of poorly inflated alveoli with PEEP will decrease the gray scale, but its interpretation as recruitment remains just that. Interestingly, the findings of Martynowicz et $\mathrm{al}^{43,44}$ are consistent with phenomena observed by Katz et al, 55 that $90 \%$ of the changes in FRC occurred within a few breaths and could be predicted accurately by baseline $\mathrm{C}_{\mathrm{RS}}$. In other words, the immediate effect of PEEP is the stabilization and improved function of patent alveoli, with recruitment being a relatively minor (in the short term), slower phenomenon. Notwithstanding, it is exceedingly difficult (if not virtually impossible) to remove the terms recruitment and de-recruitment from clinical parlance. Clinical communication must be succinct and readily understood even if it may only approximate reality.

\section{Clinical Implications}

Finally, the issue of how PEEP should be set in patients with severe hypoxemia must account for numerous potentially deleterious effects that must be balanced when treating individual patients. From a practical standpoint, it is unrealistic to expect that (1) patients without severely injured lungs require meticulous assessment of chest mechanics, and (2) most clinicians have the skill set and/or inclination to choose among numerous approaches to assess chest mechanics. This becomes even more onerous because the utility of mechanics measurements to guide PEEP settings necessitates detailed assessments that must be technically reproducible when done by numerous clinicians over the course of the acute disease process. The evidence presented here is consistent with long-held clinical opinion, namely that all but the most complex, severely ill patients with ARDS only require a relatively narrow range of PEEP. A clear and consistent pattern emerges from reviewing decades of studies on PEEP in ARDS: $10-18 \mathrm{~cm} \mathrm{H}_{2} \mathrm{O}$ PEEP is sufficient and can be adequately identified through the use of $\mathrm{PEEP} / \mathrm{F}_{\mathrm{IO}_{2}}$ tables devised by large clinical trials. In addition, automated measurements of $\mathrm{V}_{\mathrm{D}} / \mathrm{V}_{\mathrm{T}}$ are particularly sensitive not only in detecting recruitment/de-recruitment, but also overdistention, so that sophisticated measures of chest mechanics, although useful and tantalizing, are not necessary in managing the majority of patients with ARDS. This point was very elegantly stated in a recent expert review ${ }^{90}$ on PEEP:

\begin{abstract}
The 'best PEEP' does not exist. To pretend and claim that we may find a PEEP level that avoids intratidal recruitment-de-recruitment, providing in the meantime the best compliance, best oxygenation and lowest dead space without causing hyperinflation and affecting hemodynamics, reflects a wishful dream that has nothing to do with the reality. Therefore, in our opinion, we should use a 'better PEEP' approach as a reasonable compromise among oxygenation, hemodynamics status and intratidal opening and closing. Because the latter phenomenon depends quantitatively on the lung recruitability, which is a function of the lung severity, the best compromise should be the use of higher PEEP in severe ARDS (range 15-20 $\mathrm{cm} \mathrm{H}_{2} \mathrm{O}$ ), lower PEEP in mild ARDS (range 5-10 $\mathrm{cm} \mathrm{H}_{2} \mathrm{O}$ ) and intermediate in moderate ARDS, paying attention to chest wall elastance and hemodynamic impairment [emphasis added]. This pragmatic approach supported by decades of studies and experience is likely as effective as the more laborious PEEP trials that do not provide, at the end, anything else than reported ranges of values.
\end{abstract}

\section{REFERENCES}

1. Falke KJ, Pontoppidan H, Kumar A, Leith DE, Geffin B, Laver MB. Ventilation with end-expiratory pressure in acute lung disease. J Clin Invest 1972;51(9):2315-2323.

2. Suter PM, Fairley B, Isenberg MD. Optimum end-expiratory airway pressure in patients with acute pulmonary failure. N Engl J Med 1975;292(6):284-289.

3. Ashbaugh DG, Bigelow DB, Petty TL, Levine BE. Acute respiratory distress syndrome. Lancet 1967;2(7511):319-323.

4. Petty TL. In the cards was ARDS: how we discovered the acute respiratory distress syndrome. Am J Respir Crit Care Med 2001; 163(3):602-603.

5. McIntyre RW, Laws AK, Ramachandran PR. Positive end-expiratory pressure plateau: improving gas exchange during mechanical ventilation. Can Anaesth Soc J 1969;16(6):477-486.

6. Ashbaugh DG, Petty TL, Bigelow DB, Harris TM. Continuous positive-pressure breathing in adult respiratory distress syndrome. J Thorac Cardiovasc Surg 1969;57(1):31-41. 


\section{PEEP Titration Based on Chest Mechanics in ARDS}

7. Kumar A, Falke KJ, Geffin B, Aldredge CF, Laver MB, Lowenstein E, Pontoppidan H. Continuous positive-pressure ventilation in acute respiratory failure. N Engl J Med 1970;283(26):1430-1436.

8. Lutch JS, Murray JF. Continuous positive-pressure ventilation: Effects on systemic oxygen transport and tissue oxygenation. Ann Intern Med 1972;76(2):193-202.

9. Petty TL, Ashbaugh DG. The adult respiratory distress syndrome. Clinical features, factors influencing prognosis and principles of management. Chest 1971;60(3):233-239.

10. Petty TL. The use, abuse, and mystique of positive end-expiratory pressure. Am Rev Respir Dis 1988;138(2):475-478.

11. Harris RS. Pressure-volume curves of the respiratory system. Respir Care 2005;50(1):78-98; discussion 98-99.

12. Suter PM, Fairley HB, Isenberg MD. Effect of tidal volume and positive end-expiratory pressure on compliance during mechanical ventilation. Chest 1978;73(2):158-162.

13. Jardin F, Desfond P, Bazin M, Sportiche M, Margairaz A. Controlled ventilation with best positive end-expiratory pressure (PEEP) and high level PEEP in acute respiratory failure (ARF). Intensive Care Med 1981;7(4):171-176.

14. Dreyfuss D, Saumon G. Role of tidal volume, FRC, and end-inspiratory volume in the development of pulmonary edema following mechanical ventilation Am Rev Respir Dis 1993;148(5):1194-1203.

15. Kolobow T, Moretti MP, Fumagalli R, Mascheroni D, Prato P, Chen $\mathrm{V}$, Joris $\mathrm{M}$. Severe impairment in lung function induced by high peak airway pressure during mechanical ventilation: an experimental study. Am Rev Respir Dis 1987;135(2):312-315.

16. Gattinoni L, Pesenti A. ARDS: the non-homogeneous lung: facts and hypothesis. Intensive Crit Care Dig 1987;6(1):1-4.

17. Brunet F, Jeanbourquin D, Monchi M, Mira JP, Fierobe L, Armaganidis A, et al. Should mechanical ventilation be optimized to blood gases, lung mechanics, or thoracic CT scan. Am J Respir Crit Care Med 1995;152(2):524-530.

18. Gattinoni L, Pesenti A. The concept of "baby lung". Intensive Care Med 2005;31(6)776-784.

19. Molina DK, DiMaio VJ. Normal organ weights in men: part III: the brain, lungs, liver, spleen, and kidneys. Am J Forensic Med Pathol 2012;33(4):368-372.

20. Webb HH, Tierney DF. Experimental pulmonary edema due to intermittent positive pressure ventilation with high inflation pressures: protection by positive end expiratory pressure. Am Rev Resir Dis 1974;110(5):556-565.

21. Gattinoni L, Carlesso, Cadringher P, Valenza F, Vagginelli F, Chiumello D. Physical and biological triggers of ventilator induced lung injury and its prevention. Eur Respir J Suppl 2003;47:15s-25s.

22. Rocco PRM, Dos Santos C, Pelosi P. Pathophysiology of ventilatorassociated lung injury. Curr Opin Anaesthesiol 2012;25(2):123-130.

23. Amato MBP, Barbas CSV, Medeiros DM, Schettino Gde P, Lorenzi Filho G, Kairalla RA, et al. Beneficial effects of the "open lung approach" with low distending pressures in acute respiratory distress syndrome. Am J Respir Crit Care Med 1995;152(6):1835-1846.

24. Bellani G, Messa C, Guerra L, Spagnolli E, Foti G, Patroniti N, et al. Lungs of patients with acute respiratory distress syndrome show diffuse inflammation in normally aerated regions: a $\left[{ }^{18} \mathrm{~F}\right]$-fluoro-2deoxy-D-glucose PET/CT study. Crit Care Med 2009;37(7):22162222.

25. Lemaire F, Simoneau G, Harf A, Rivara D, Teisseire B, Atlan G, Rapin M. Static pulmonary pressure-volume (P-V) curve, positive end-expiratory pressure (PEEP) ventilation and gas exchange in acute respiratory failure (ARF). Am Rev Respir Dis 1979;119:328.

26. Amato MBP, Barbas CSV, Medeiros DM, Magaldi RB, Schettino GP, Lorenzi-Filho G, et al. Effect of a protective-ventilation strategy on mortality in the acute respiratory distress syndrome. N Engl J Med 1998;338(6):347-354.
27. Villar J, Kacmarek RM, Pérez-Méndez L, Aguirre-Jaime A. A high positive end-expiratory pressure, low tidal volume ventilatory strategy improves outcome in persistent acute respiratory distress syndrome: a randomized controlled trial. Crit Care Med 2006;34(5): 1311-1318

28. Roupie E, Dambrosio M, Servillo G, Mentec H, el Atrous S, Beydon $\mathrm{L}$, et al. Titration of tidal volume and induced hypercapnia in acute respiratory distress syndrome. Am J Respir Crit Care Med 1995; 152(1):121-128.

29. Ranieri VM, Suter PM, Tortorella C, De Tullio R, Dayer JM, Brienza A, et al. Effect of mechanical ventilation on inflammatory mediators in patients with acute respiratory distress syndrome: a randomized controlled trial. JAMA 1999;282(1):54-61.

30. The ARDS Clinical Trials Network. A trial of traditional tidal volume versus lower tidal volume ventilation in acute lung injury and acute respiratory distress syndrome. N Engl J Med 2000;342(18): 1301-1308.

31. Terragni PP, Rosboch G, Tealdi A, Corno E, Menaldo E, Davini O, et al. Tidal hyperinflation during low tidal volume ventilation in acute respiratory distress syndrome. Am J Respir Crit Care Med 2007;175(2):160-166.

32. Mols G, Brandes I, Kessler V, Lichtwarck-Aschoff M, Loop T, Geiger K, Guttmann J. Volume-dependent compliance in ARDS: proposal of a new diagnostic concept. Intensive Care Med 1999; 25(10):1084-1091.

33. Ranieri VM, Zhang H, Mascia L, Aubin M, Lin CY, Mullen JB, et al. Pressure time curve predicts minimally injurious ventilatory strategy in an isolated rat lung model. Anesthesiology 2000;93(5): 1320-1328.

34. Grasso S, Terragni P, Mascia L, Fanelli V, Quintel M, Herrmann P, et al. Airway pressure-time curve profile (stress index) detects tidal recruitment/hyperinflation in experimental acute lung injury. Crit Care Med 2004;32(4):1018-1027.

35. Grasso S, Stripoli T, De Michele M, Bruno F, Moschetta M, Angelelli G, et al. ARDSnet ventilatory protocol and alveolar hyperinflation. Am J Respir Crit Care Med 2007;176(8):761-767.

36. Terragni PP, Filippini C, Slutsky AS, Birocco A, Tenaglia T, Grasso $S$, et al. Accuracy of plateau pressure and stress index to identify injurious ventilation in patients with acute respiratory distress syndrome. Anesthesiology 2013;119(4):880-889.

37. Vieillard-Baron A, Schmitt JM, Augarde R, Fellahi JL, Prin S, Page $\mathrm{B}$, et al. Acute cor pulmonale in acute respiratory distress syndrome submitted to protective ventilation: incidence, clinical implications and prognosis. Crit Care Med 2001;29(8):1551-1555.

38. Ferrando C, Suárez-Sipmann F, Gutierrez A, Tusman G, Carbonell J, García M, et al. Adjusting tidal volume to stress index in an open lung condition optimizes ventilation and prevents overdistension in an experimental model of lung injury and reduced chest wall compliance. Crit Care 2015;19:9.

39. Talmor D, Sarge T, Malhotra A, O'Donnell CR, Ritz R, Lisbon A, et al. Mechanical ventilation guided by esophageal pressure in acute lung injury. N Engl J Med 2008;359(20):2095-2104.

40. Fish E, Novack V, Banner-Goodspeed VM, Sarge T, Loring S, Talmor D. The esophageal pressure-guided ventilation 2 (EPVent2) trial protocol: a multicentre, randomized clinical trial of mechanical ventilation guided by transpulmonary pressure. BMJ Open 2014(9);4: e006356.

41. Briel M, Meade M, Mercat A, Brower RG, Talmor D, Walter SD, et al. Higher vs lower positive end-expiratory pressure in patients with acute lung injury and acute respiratory distress syndrome. JAMA 2010;303(9):865-873.

42. Gattinoni L, D'Andrea L, Pelosi P, Vitale G, Pesenti A, Fumagalli R. Regional effects and mechanism of positive end-expiratory pressure 


\section{PEEP Titration Based on Chest Mechanics in ARDS}

in early adult respiratory distress syndrome. JAMA 1993;269(16): 2122-2127.

43. Martynowicz MA, Minor TA, Walters BJ, Hubmayr RD. Regional expansion of the oleic acid-injured lungs. Am J Respir Crit Care Med 1999;160(1):250-258.

44. Martynowicz MA, Walters BJ, Hubmayr RD. Mechanisms of recruitment in oleic acid-injured lungs. J Appl Physiol 2001;90(5): 1744-1753.

45. Hubmayr RD. Perspective on lung injury and recruitment: a skeptical look at the opening and collapse story. Am J Respir Crit Care Med 2002;165(12):1647-1653.

46. Albert RK. Least PEEP: primum non nocere. Chest 1985;87(1):2-4.

47. Stewart TE, Meade MO, Cook DJ, Granton JT, Hodder RV, Lapinsky SE, et al. Evaluation of a ventilation strategy to prevent barotrauma in patients at high risk for acute respiratory distress syndrome. N Engl J Med 1998;338(6):355-361.

48. Brochard L, Roudot-Thoraval F, Roupie E, Delclaux C, Chastre J, Fernandez-Mondéjar E, et al. Tidal volume reduction for prevention of ventilator-induced lung injury in acute respiratory distress syndrome. Am J Respir Crit Care Med 1998;158(6):1831-1838.

49. Brower RG, Shanholtz CB, Fessler HE, Shade DM, White P Jr, Wiener CM, et al. Prospective, randomized, controlled clinical trial comparing traditional versus reduced tidal volume ventilation in acute respiratory distress syndrome patients. Crit Care Med 1999;27(8): 1492-1498

50. Brower RG, Lanken PN, MacIntyre N, Matthay MA, Morris A, Ancukiewicz M, et al. Higher versus lower positive end-expiratory pressures in patients with the acute respiratory distress syndrome. N Engl J Med 2004;351(4):327-336.

51. National Heart, Lung, and Blood Institute Acute Respiratory Distress Syndrome (ARDS) Clinical Trials Network, Wiedemann HP, Wheeler AP, Bernard GR, Thompson BT, Hayden D, et al. Comparison of two fluid-management strategies in acute lung injury. N Engl J Med 2006;354(24):2564-2575

52. Meade MO, Cook DJ, Guyatt GH, Slutsky AS, Arabi YM, Cooper DJ, et al. Ventilation strategy using low tidal volumes, recruitment maneuvers and high positive end-expiratory pressure for acute lung injury and acute respiratory distress syndrome. JAMA 2008;299(6): 637-645.

53. National Heart, Lung, and Blood Institute ARDS Clinical Trials Network, Truwit JD, Bernard GR, Steingrub J, Matthay MA, Liu $\mathrm{KD}$, et al. Rosuvastatin for sepsis-associated acute respiratory distress syndrome. N Engl J Med 2014;370(23):2191-2200.

54. Mercat A, Richard JCM, Vielle B, Jaber S, Osman D, Diehl JL, et al. Positive end-expiratory pressure setting in adults with acute lung injury and acute respiratory distress syndrome. JAMA 2008;299(6): 646-655.

55. Katz JA, Ozanne GM, Zinn SE, Fairley HB. Time course and mechanism of lung-volume increases with PEEP in acute pulmonary failure. Anesthesiology 1981;54(1):9-16.

56. Pelosi P, Cadringher P, Bottino N, Panigada M, Carrieri F, Riva E, et al. Sigh in acute respiratory distress syndrome. Am J Respir Crit Care Med 1999;159(3):872-880.

57. Huang Y, Yang Y, Chen Q, Liu S, Liu L, Pan C, et al. Pulmonary acute respiratory distress syndrome: positive end-expiratory pressure titration needs stress index. J Surg Res 2013;185(1):347-352.

58. Amato MB, Meade MO, Slutsky AS, Brochard L, Costa EL, Schoenfeld DA, et al. Driving pressure and survival in the acute respiratory distress syndrome. N Engl J Med 2015;372(8):747-755.

59. Ward NS, Lin DY, Nelson DL, Houtchens J, Schwartz WA, Klinger JR, et al. Successful determination of lower inflection point and maximal compliance in a population of patients with acute respiratory distress syndrome. Crit Care Med 2002;30(5):963-968.
60. Kallet RH. Pressure-volume curves in the management of acute respiratory distress syndrome. Respir Care Clin N Am 2003;9(3):321341 .

61. Kallet RH, Branson RD. Do the NIH ARDS clinical trials network $\mathrm{PEEP} / \mathrm{F}_{\mathrm{IO}_{2}}$ tables provide the best evidence-based guide to balancing PEEP and $\mathrm{F}_{\mathrm{IO}_{2}}$ settings in adults? Respir Care 2007;52(4):461-475; discussion 475-477.

62. Hickling KG. The pressure-volume curve is greatly modified by recruitment: a mathematical model of ARDS lungs. Am J Respir Crit Care Med 1998:158(1):194-202.

63. Mergoni M, Volpi A, Bricchi C, Rossi A. Lower inflection point and recruitment with PEEP in ventilated patients with acute respiratory failure. J Appl Physiol 2001;91(1):441-450.

64. Medoff BD, Harris RS, Kesselman H, Venegas J, Amato MBP, Hess D. Use of recruitment maneuvers and high positive end-expiratory pressure in a patient with acute respiratory distress syndrome. Crit Care Med 2000;28(4):1210-1216.

65. Pelosi P, Goldner M, McKibben A, Adams A, Eccher G, Caironi P, et al. Recruitment and derecruitment during acute respiratory failure: an experimental study. Am J Respir Crit Care Med 2001;164(1):122130.

66. Crotti S, Mascheroni D, Caironi P, Pelosi P, Ronzoni G, Mondino M, et al. Recruitment and derecruitment during acute respiratory failure: a clinical study. Am J Respir Crit Care Med 2001;164(1):131-140.

67. Vieira SRR, Puybasset L, Lu Q, Richecoeur J, Cluzel P, Coriat P, Rouby JJ. A scanographic assessment of pulmonary morphology in acute lung injury. Am J Respir Crit Care Med 1999;159(5):16121623 .

68. Mergoni M, Martelli A, Volpi A, Primavera S, Zuccoli P, Rossi A Impact of positive end expiratory pressure on chest wall and lung pressure-volume curve in acute respiratory failure. Am J Respir Crit Care Med 1997;156(3):846-854.

69. Broseghini C, Brandolese R, Poggi R, Polese G, Manzin E, MilicEmili J, Rossi A. Respiratory mechanics during the first day of mechanical ventilation in patients with pulmonary edema and chronic airway obstruction. Am Rev Respir Dis 1988;138(2):355-361.

70. Vieillard-Baron A, Prin S, Schmitt JM, Augarde R, Page B, Beauchet A, Jardin F. Pressure-volume curves in acute respiratory distress syndrome. Am J Respir Crit Care Med 2002;165(8):1107-1112.

71. Sohma A, Brampton WJ, Dunnill MS, Sykes MK. Effect of ventilation with positive end-expiratory pressure on the development of lung damage in experimental acid aspiration pneumonia in the rabbit. Intensive Care Med 1992;18(2):112-117.

72. Dambrosio M, Roupie E, Mollet JJ, Anglade MC, Vasile N, Lemaire F, Brochard L. Effects of positive end-expiratory pressure and different tidal volumes on alveolar recruitment and hyperinflation. Anesthesiology 1997;87(3):495-503.

73. Lichtwarck-Aschoff M, Mols G, Hedlund AJ, Kessler V, Markström $\mathrm{AM}$, Guttmann J, et al. Compliance is nonlinear over tidal volume irrespective of positive end-expiratory pressure level in surfactantdepleted piglets. Am J Respir Crit Care Med 2000;162(6):21252133

74. Beydon L, Jonson B, Lemaire F. Lung mechanics in ARDS: compliance and the pressure-volume curves. In: Zapol WM, Lemaire F, editors. Adult respiratory distress syndrome. New York: Marcel Dekker 1991;139-161.

75. Hickling KG. Best compliance during a decremental, but not incremental, positive end-expiratory pressure trial is related to open-lung positive end-expiratory pressure. Am J Respir Crit Care Med 2001; 163(1):69-78

76. Albaiceta GM, Taboada F, Parra D, Luyando LH, Calvo J, Menendez R. Tomographic study of the inflection points of the pressurevolume curve in acute lung injury. Am J Respir Crit Care Med 2004;170(10):1066-1072. 


\section{PEEP Titration Based on Chest Mechanics in ARDS}

77. Albaiceta GM, Luyando LH, Parra D, Menendez R, Calvo J, Pedreira PR, Taboada F. Inspiratory vs. expiratory pressure-volume curves to set end-expiratory pressure in acute lung injury. Intensive Care Med 2005;31(10):1370-1378.

78. Kallet RH, Katz JA. Respiratory system mechanics in acute respiratory distress syndrome. Respir Care Clin N Am 2003;9(3):297319.

79. Bull TM, Clark B, McFann K, Moss M, National Institutes of Health/National Heart, Lung, and Blood Institute ARDS Network. Pulmonary vascular dysfunction is associated with poor outcomes in patients with acute lung injury. Am J Respir Crit Care Med 2010; 182(9):1123-1128.

80. Boissier F, Katsahian S, Razazi K, Thille AW, Roche-Campo F, Leon R, et al. Prevalence and prognosis of cor pulmonale during protective ventilation for acute respiratory distress syndrome. Intensive Care Med 2013;39(10):1725-1733.

81. Borges JB, Okamoto VN, Matos GFJ, Caramez MPR, Arantes PR, Barros F, et al. Reversibility of lung collapse and hopoxemia in early acute respiratory distress syndrome. Am J Respir Crit Care Med 2006;174(3):268-278.

82. Girgis K, Hamed H, Khater Y, Kacmarek RM. A decremental PEEP trial identifies the PEEP level that maintains oxygenation after lung recruitment. Respir Care 2006;51(10):1132-1139.

83. Huh JW, Jung H, Choi HS, Hong SB, Lim CM, Koh Y. Efficacy of positive end-expiratory pressure titration after the alveolar recruitment manoeuvre in patients with acute respiratory distress syndrome. Crit Care 2009;13(1):R22.
84. Badet M, Bayle F, Richard JC, Guérin C. Comparison of optimal positive end-expiratory pressure and recruitment maneuvers during lung protective mechanical ventilation in patients with acute lung injury/acute respiratory distress syndrome. Respir Care 2009;54(7): 847-854.

85. Fengmei G, Jin C, Songqiao L, Congshan Y, Yi Y. Dead space fraction changes during PEEP titration following lung recruitment in patients with ARDS. Respir Care 2012;57(10):1578-1585.

86. Rodriguez PO, Bonelli I, Setten M, Attie S, Madorno M, Maskin LP, Valentini R. Transpulmonary pressure and gas exchange during decremental PEEP titration in pulmonary ARDS patients. Respir Care 2013;58(5):754-763.

87. Kallet RH. Measuring dead-space in acute lung injury. Minerva Anestesiol 2012;78(11):1297-1305.

88. Tusman G, Suarez-Sipmann F, Böhm SH, Pech T, Reissmann H, Meschino G, et al. Monitoring dead space during recruitment and PEEP titration in an experimental model. Intensive Care Med 2006; 32(11):1863-1871

89. Maisch S, Reissmann H, Fuellekrug B, Weismann D, Rutkowski T, Tusman G, Bohm SH. Compliance and dead space fraction indicate an optimal level of positive end-expiratory pressure after recruitment in anesthetized patients. Anesth Analg 2008;106(1):175-181, table of contents.

90. Gattinoni L, Carlesso E, Cressoni M. Selecting the "right" positive end-expiratory pressure level. Curr Opin Crit Care 2015;21(1):5057.

\section{Discussion}

Branson: I think over the years, the arguments at these conferences about how to set PEEP have probably been some of the most aggressive. But right now it seems like everybody has come to a reasonable approach, expressed by Rich's last slide. Does anybody have a big concern?

Marini: Rich, your presentation was both comprehensive and well balanced. Many things come to mind here. The chest wall does play a part in what we interpret from mechanical ventilation data, and the objectives for setting PEEP are multiple. They're not just oxygenation; it's recruitment, lung protection, prevention of hemodynamic compromise. We know that if you go from 0 volume to total lung capacity in a patient with injured lungs, that there'll be continuous recruitment going up and de-recruitment going down. It's not just the properties of the individual alveolus that change, but the number of lung units that you're recruiting. You're always going to leave some units un-recruited, and as you get to higher pressures, you are increasing the risk for any that stay collapsed. Whether you believe it's opening and closure or the tension on those tissues that is damaging, you're upping the ante any time you raise the PEEP beyond a reasonable level. I'm a little concerned about using dead space- one of the annoying things about $\mathrm{CO}_{2}$ production is that it's quite variable in unstable patients. Acidosis and metabolic change can generate $\mathrm{CO}_{2}$ and affect the interpretation of the dead space. So, I don't know how consistent it is as an indicator for sick patients. I share your admiration for Jeffrey Katz; I met him a couple of times in my early years, and he impressed me as an assertive guy who was usually right. One of the lessons I took from his work is that if you made a stepwise change of $10 \mathrm{~cm} \mathrm{H}_{2} \mathrm{O}$ in PEEP of sedated, paralyzed patients in the OR, you achieved the eventual FRC only after $20-40 \mathrm{~s}$ or about 8 breaths. I think the " $40 \mathrm{~cm} \mathrm{H}_{2} \mathrm{O}$ : 40 second" recruitment rule we formerly used came from the fact that after a step change in PEEP, you have to wait to equilibrate mechanically. Again, you assessed complicated issues very nicely-thanks.

Kallet: The issues with dead-space changes are not perfect, but I think they're very useful, particularly when making observations about the impact of vent changes over a short-term period. It's also a harbinger for someone who's losing their cardiac output the response of vasoconstriction (to support arterial blood pressure) if they're able to do that will mask decreased cardiac output, whereas you can see the $\mathrm{V}_{\mathrm{CO}_{2}}$ drop very quickly. At least it's a tool in the tool chest. I'm a big believer in mechanics, and there's nothing I love more than to have numerous variables to look at in complicated patients to watch their physiology and how it responds to therapy. But what are we after here in terms of a take-home message for clinicians? What is really necessary? For most patients, this is not that complicated; they don't need very high levels of PEEP. If you look at the meta-analy- 
sis of the high PEEP studies, the mortality was higher in subjects on high PEEP who had ALI [acute lung injury]. They were over-PEEP'd, and there's probably some detrimental effects to that. So we reserve this for a small number of patients where we really need to focus and apply mechanics and esophageal manometry. The sickest ones where I think the small amount of information we get from these adjustments may be crucial. But for a lot of patients, I don't think it's really necessary.

Marini: When we manage patients in the semi-supine position-you anesthesiologists can tell us better-you lose a lot of volume. In a normal individual, I think you lose about $1 \mathrm{~L}$ going upright to horizontal. And to restore that $\mathrm{FRC}$ would require at least 5 and maybe closer to $8 \mathrm{~cm} \mathrm{H}_{2} \mathrm{O}$. I virtually never use 0 PEEP, and that's something we should emphasize in the discussion here.
Hurford: There have been some nice CT studies in both normal and obese subjects looking at induction of anesthesia, and as you expect, there's a large amount of vasoatelectasis that quickly develops within minutes. And is reversed by CPAP or PEEP, generally at a level of 8-10 $\mathrm{cm} \mathrm{H}_{2} \mathrm{O}$. The standard in an old-fashioned anesthesia ventilator where you have 0 PEEP, I think that's now gone away. The majority of patients receive at least $5 \mathrm{~cm}$ $\mathrm{H}_{2} \mathrm{O}$ of PEEP, even in a healthy lung.

Marini: Great. Lastly, about tidal compliance. I don't know if we'll have agreement around the table on what I say next, but it can be tricky to interpret. I was talking with Dean [Hess] last night about my experience with unilateral pleural effusion in a patient who had ARDS, as some do. It turns out that as you build airway pressure, you push mobile pleural fluid out of the way of the expanding lung. If the abdomen is flexible, the tidal compliance measurement gives you very mis- leading information regarding what is actually happening to the underlying lung of interest-opening and closure of the tissue surrounded by the pleural liquid. The tidal compliance can be nearly normal although at FRC you have many lung units collapsed. This occurs because you're recruiting extensively during the tidal breath. For example, $10 \mathrm{~cm} \mathrm{H}_{2} \mathrm{O}$ of airway pressure would push a hydrostatic column of that depth into the gutters and temporarily free up the adjacent lung tissue. We've published this, ${ }^{1}$ but it's a buffer that affects the validity of the airway pressure-based signal that we traditionally use- the one that is easy to record. It shocked the heck out of me the first time I realized what was happening.

\section{REFERENCE}

1. Graf J, Formenti P, Santos A, Gard K, Adams A, Tashjian J, et al. Pleural effusion complicates monitoring of respiratory mechanics. Crit Care Med 2011;39(10):22942299. 